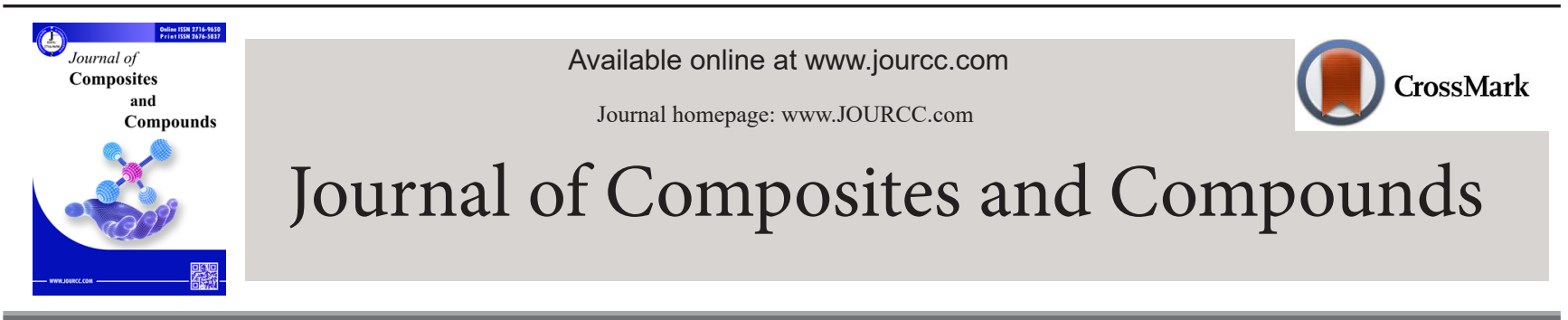

\title{
A review on the mechanical properties of synthetic and natural fiber-reinforced polymer composites and their application in the transportation industry
}

\author{
Leila Bazli $^{a} \mathbb{C}^{0}$, Milad Bazli $^{b *}$ \\ ${ }^{a}$ School of Metallurgy and Materials Engineering, Iran University of Science and Technology, Tehran, Iran \\ ${ }^{b}$ College of Engineering, IT \& Environment, Charles Darwin University, Darwin, Australia
}

\section{A B S T R A C T}

A R T I CLE IN F O RMA T I ON

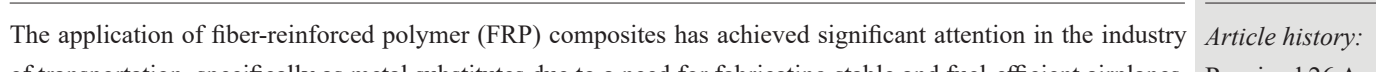

of transportation, specifically as metal substitutes due to a need for fabricating stable and fuel-efficient airplanes, Received 26 August 2021

vehicles, and ships. Excellent strength, resistance to corrosion, lightweight, and suitable fatigue endurance are Received in revised form 19 November 2021 some of the desirable properties that would encourage the use of FRP composites in the transportation sector. Accepted 26 December 2021

Polymer-based composite materials, combining the favorable properties of both polymer matrix and reinforcing fibers, can contribute to several excellent behaviors of the obtained material. Epoxy, polyethylene, and polypropylene are the primary polymer matrices used in FRP composites. The main reinforcing fibers incorporated in Keywords: fiber-reinforced composites are made out of glass, carbon, basalt, hemp, or natural resources (e.g., sisal and jute). Fiber-reinforced composites Due to high cost, low Young's modulus, low durability, and linear stress-strain behavior to failure of the FRP mate- Polymer composites rials, which are used in transportation infrastructure, the objective of this review article is to study the recent aspect Mechanical properties of reinforced polymers with a close focus on their mechanical properties in order to evaluate their application in Transportation industry maritime, automotive, and aerospace.

(C)2021 JCC Research Group.

Peer review under responsibility of JCC Research Group

Table of contents

1. Introduction

2. Fiber-reinfored polymer composites

2.1. Glass fibers

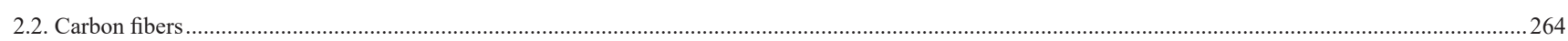

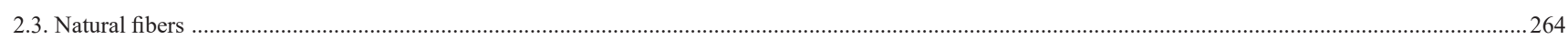

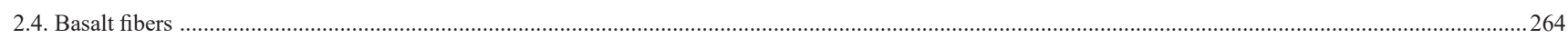

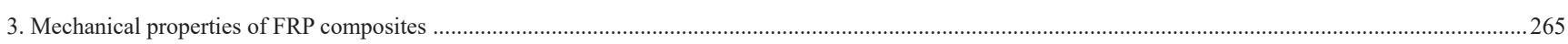

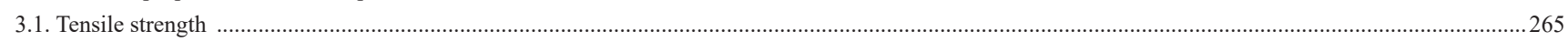

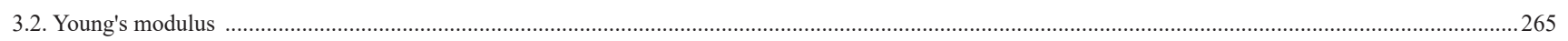

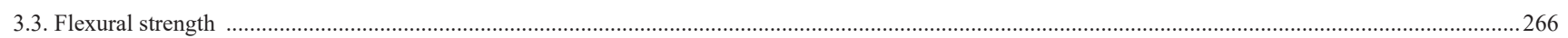

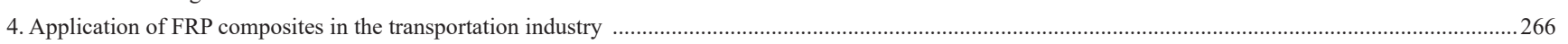

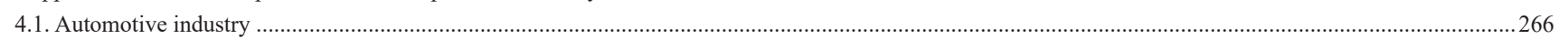

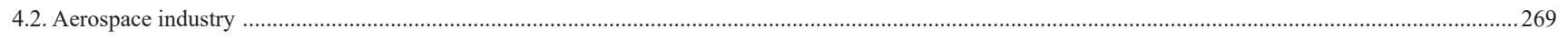

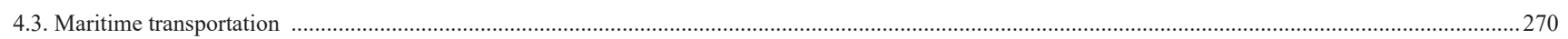

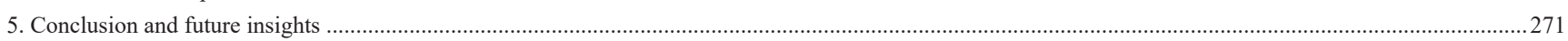

\section{Introduction}

High-strength fibers with different positions and directions can be incorporated in polymer matrices. These materials are the constituent elements of fiber-reinforced polymeric materials. Fibers are the load-carrying elements that provide rigidity and strength $[1,2]$. Therefore, fiber-rein- forced polymer matrices will be protected against damage and other environmental risk factors $[3,4]$. Pure polymers alone do not have sufficient strength; when reinforced with fibers, they are provided with high mechanical strength and are used in various applications such as the aerospace industry, construction, automation, sports equipment, etc. [58]. Glass, aramid, carbon, Kevlar, etc. are the components of synthetic fiber-reinforced polymer composite (SFRPC) which have high strength and hardness, longer fatigue life, and more compatibility with the de- 


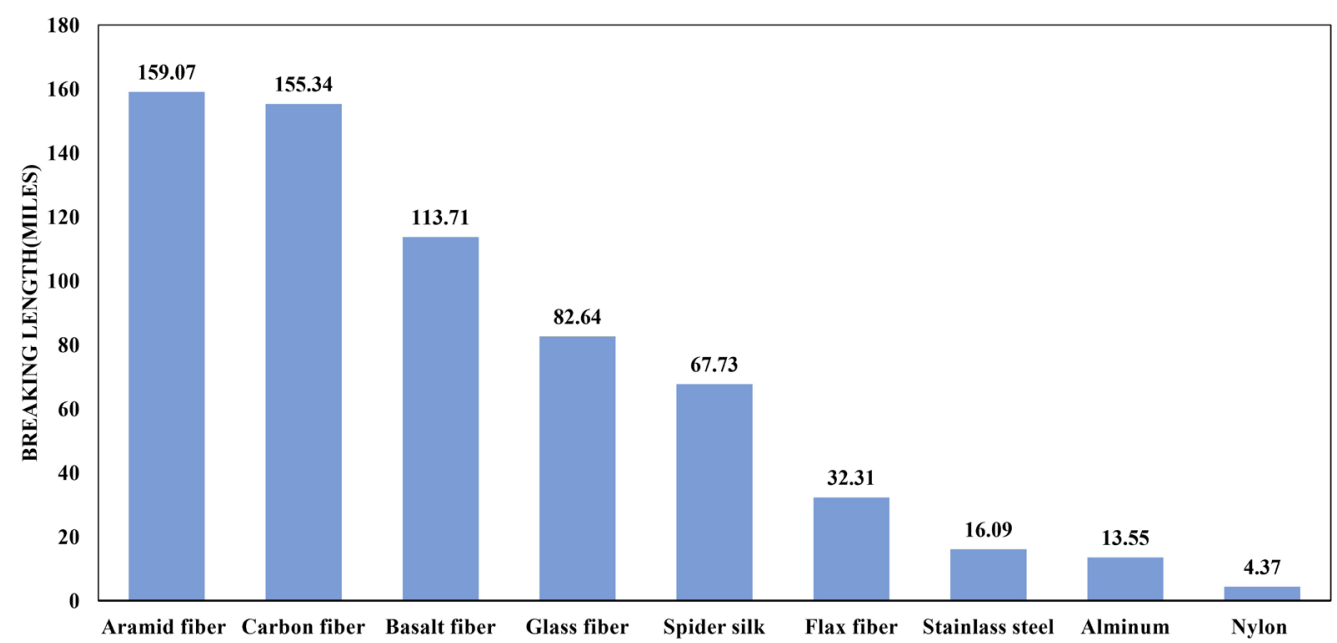

Fig. 1. Breaking length of materials (miles).

sired performance of structures than monolithic polymer materials [911]. The main advantages of synthetic FRPCs are conductivity, thermal insulation, environmental stability, temperature-dependent behavior, appearance, abrasion resistance, and corrosion resistance [12-14].

These materials have been employed in many fields because of their low density, high strength, and stiffness-to-weight ratio as well as corrosion resistance in comparison with other metals $[15,16]$. One of the main fields of FRP application is the transportation industry, automobiles, aerospace, and ship structures. On the other hand, these materials have disadvantages including biodegradable features, poor recycling, and high cost and density (in comparison with other polymers. Using natural plant fibers reinforced polymer composites (NFRPC) has been considered recently to overcome such drawbacks [17]. The advantages of natural fiber-reinforced composites with thermoplastic matrices are their biodegradability, low cost, lightweight, satisfactory strength of modulus, and accessibility of renewable natural sources [18-21]. However, NFRPCs have less mechanical strength than SFRPCs and therefore cannot replace SFRPCs in several applications. Several research studies have been conducted in recent decades which has improved the performance of natural fibers including jute [22, 23], flax [24], sisal [25, 26], hemp [27,28], and so on but their inherent properties of biodegradability and low specific gravity remain unchanged.

This study aims to review recent studies on improving the characteristics of polymer composites including different kinds of fibers and polymers from synthetic to natural fibers and compare their mechanical properties and applications in the transportation industry.

\section{Fiber-reinforced polymer composites}

Composites are made of more than two different and separate chemical components on a macro scale. As a result, one or more discontinuous phases are required to be incorporated in a continuous phase to form a composite material. The continuous phase is known as the matrix, and the discontinuous phase is called reinforcement because it is stronger and harder than the continuous phase [29-31]. FRPs contain fibers with high modulus and high strength which are bonded or embedded in a matrix while a distinct interface exists between them [32]. Fibers and matrices each have their own unique physical and chemical properties. The fibers are responsible for carrying the load, and the matrices keep the fibers in the right place and direction, transferring the load between them and protecting them from environmental damage [33].

There are several types of polymer matrices, including thermosetting resins and thermoplastic resins. Thermoplastics themselves include acrylonitrile butadiene styrene (ABS) resins, polyethylene (PE), and polypropylene (PP) as well as engineering plastics including polyetherimide (PEI), polyetheretherketone (PEEK), polyethersulfone (PES), polyphenylene sulfide (PPS), polycarbonate (PC), and polyamide (PA). Thermoplastics do not require a curing step, also their chemical compositions are less hazardous, easier to be recycled, and mass-produced in comparison with conventional thermosetting. The conventional molding techniques that are used for the fabrication of thermoplastic resins include injection molding, vacuum forming, extrusion, rotational molding, and compression molding [7, 33, 34]. Characteristics of low-mass fiber-reinforced polymers include lower density compared to conventional resins and thermoplastic polymers, good mechanical properties, highstrength fiber reinforcement, and specific gravity. They are resistant to corrosion and have the ability to dampen mechanical vibrations [35, 36].

Fibers can also be divided into natural and synthetic fibers. Synthetic fibers are formed by extruding building material fibers through spinners into air and water to create a thread. Synthetic fibers can be glass, carbon, aramid, or basalt [37, 38]. In addition, other materials, such as paper, wood, or asbestos, are sometimes used to make fibers. The use of synthetic materials to prepare fibers has advantages such as; high strength, rigidity, fatigue life, and wear resistance. On the other hand,

Table 1.

Chemical compositions of different glass fibers in wt. \%

\begin{tabular}{cccccccccc}
\hline Type & $\mathbf{S i O}_{2}$ & $\mathrm{Al}_{2} \mathbf{O}_{3}$ & $\mathrm{TiO}_{2}$ & $\mathbf{B}_{2} \mathbf{O}_{3}$ & $\mathbf{C a O}$ & $\mathbf{M g O}$ & $\mathbf{N a}_{2} \mathbf{O}$ & $\mathbf{K}_{2} \mathbf{O}$ & $\mathbf{F e}_{2} \mathbf{O}_{3}$ \\
\hline E-glass & 55.0 & 140 & 0.2 & 7.0 & 22.0 & 1.0 & 0.5 & 0.3 & - \\
C-glass & 64.6 & 41 & - & 5.0 & 13.4 & 3.3 & 9.6 & 0.5 & - \\
S-glass & 65.0 & 25.0 & - & - & - & 10.0 & - & - & - \\
A-glass & 67.5 & 3.5 & - & 1.5 & 6.5 & 4.5 & 13.5 & 3.0 & - \\
D-glass & 740 & - & - & 22.5 & - & - & 1.5 & 2.0 & - \\
R-glass & 600 & 24.0 & - & - & 9.0 & 6.0 & 0.5 & 0.1 & - \\
EGR-glass & 61.0 & 13.0 & - & - & 22.0 & 3.0 & - & 0.5 & - \\
Basalt & 520 & 17.2 & 1.0 & - & 8.6 & 5.2 & 5.0 & 1.0 & 5.0 \\
\hline
\end{tabular}




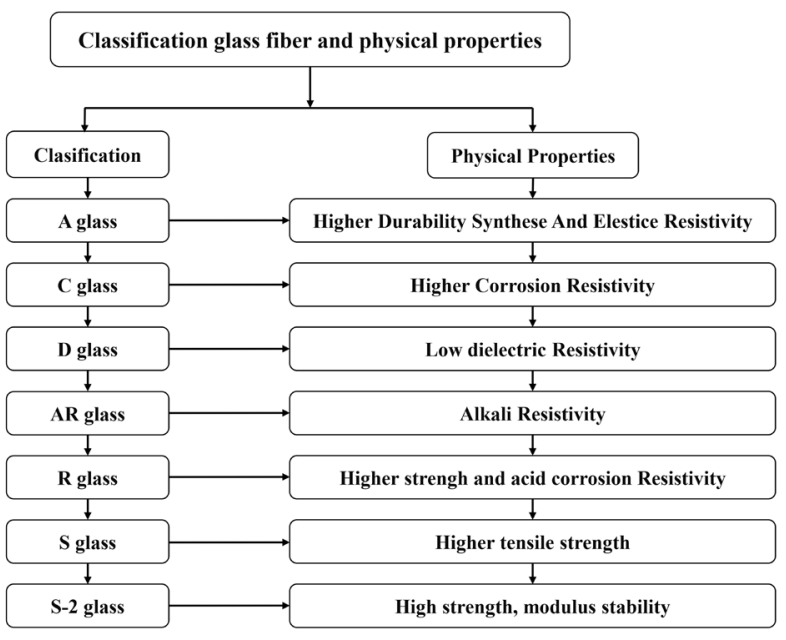

Fig. 2. Classification and physical characteristics of different glass fibers.

their disadvantages include high cost, and poor recycling and biodegradability. Using polymer composites with natural fibers has advantages over ordinary glass and carbon. As a result, researchers and scientists have been significantly interested in these materials. Natural fibers are made from animal and plant hair. Their advantages over synthetic fibers are lower cost and improved stability. The use of biofibers like bamboo, hemp, vetiver, sisal, jute, etc. has both advantages of reasonable cost and availability. These natural fibers have acceptable mechanical properties and are environmentally safe [39-44]. Other studies have shown that in addition to good mechanical properties, they have low density and low price [44]. As a result, these materials are used in the automotive industry because of their unique properties $[45,46]$. In addition to the advantages mentioned for natural fibers, their disadvantage may be an incompatibility with hydrophobic polymer matrix. To solve their hydrophobicity in polymer matrices, different chemical strategies like acid, acetylation, and silane have been used [33].

In various industries such as automotive, aerospace, and maritime, the relatively superior specific strength of polymer matrix composites (PMC) reduces the final structural element weights. In the transportation industry, the use of materials with high strength and low weight has recently been considered. The specific strength properties of materials are the most important feature for their evaluation in these industries [47, 48]. Fig. 1 shows the breaking length of the selected materials. In the following sections, the most common synthetic and natural fibers used in FRPs and their properties are discussed.

\subsection{Glass fibers}

The most typical FRP type is glass-fiber-reinforced polymer composites (GFRP) $[49,50]$. The matrix includes epoxy resins, phenolic, vinyl ester, thermostable, polyester, and organic polymers. Bisphenol and ortho or isophthalic are two kinds of polyester resins [51]. The advantages of glass fibers include elasticity, desirable insulation, chemical resistance, and superior strength. Various kinds of glasses are shown in Fig. 2, including D glass, E glass, S glass, A glass, and so on. Because

Table 2.

Chemical composition of natural fibers

\begin{tabular}{|c|c|c|c|c|c|c|}
\hline$\%$ & Cotton & Jute & Flax & Hemp & Kenaf & Sisal \\
\hline Lignin & - & $12-13$ & 2.2 & $\begin{array}{c}3.7- \\
5.7\end{array}$ & $\begin{array}{c}5.9- \\
9.3\end{array}$ & $8-11$ \\
\hline Hemicelluloses & 5.7 & $\begin{array}{l}13.6- \\
20.6\end{array}$ & $\begin{array}{l}18.6- \\
20.6\end{array}$ & $\begin{array}{l}17.9- \\
22.4\end{array}$ & $15-19$ & $\begin{array}{c}10- \\
14.2\end{array}$ \\
\hline Cellulose & 82.7 & $61-71$ & $\begin{array}{l}71- \\
75\end{array}$ & $\begin{array}{l}70.2- \\
74.4\end{array}$ & $53-57$ & $\begin{array}{l}67- \\
78\end{array}$ \\
\hline
\end{tabular}

of their superior tensile strength, the most common types can be $\mathrm{S}$ glass and $\mathrm{E}$ glass. Woven cloth, chopped fibers, and long continuous fibers are three forms of commercially available glass fibers. Woven cloths are fabricated from long perpendicular fibers. To make these fibers, long fibers are cut and arranged in batches. Electronic glass (E-glass) fibers are used when the budget is low, such as household products including sports products, window frames, fiberglass doors, etc. $\mathrm{S}$ glass fibers can be applied in cases where strength is more important than the financial budget. S glass fibers can be employed in the fabrication of vehicle components, tail wings of airplanes, ship hulls, etc $[25,52,53]$. Table 1 shows the chemical composition of various glass fibers.

\subsection{Carbon fibers}

Due to having properties like high wear resistance, high modulus, and high specific tensile strength, carbon fibers ( $\mathrm{CFs}$ ) have been used as reinforcing materials to composites. In CF-reinforced composites, the polymer is a continuous matrix and a $\mathrm{CF}$ is a discontinuous phase. Based on their length, $\mathrm{CFs}$ are divided into short $\mathrm{CFs}$ ( $\mathrm{SCFs}$ ), long $\mathrm{CFs}$, and continuous CFs. Due to their excellent mechanical properties and low density, these carbon-reinforced polymers (CFRP) have been used in many fields including the sporting goods industries, transportation, and aerospace [7, 34].

\subsection{Natural fibers}

For the past 30 years, researchers have used NFRPCs to replace synthetic fibers in order to make FRPs more environmentally friendly and decrease the traditional fiber costs (glass and carbon). Natural fibers have a low density and their composites are light in weight and have desirable properties. Other advantages of using natural fibers include renewability, biodegradability, low cost, and requiring low energy processing $[54,55]$. Consequently, due to the mentioned advantages such as lightweight and low cost, these fibers such as coir, abacus, sisal, hemp, flax, and jute are suitable alternatives to synthetic fibers. In previous studies, thermosetting and thermoplastic polymers have been investigated as binders in NFRPCs. In this field, most studies have been done on unsaturated polyesters and epoxy resins. Among thermoplastics, polyolefin including polypropylene as well as low and high-density polyethylene are significantly considered [56-58]. Table 2 gives the contents (cellulose, hemicellulose, and lignin) of some natural fiber compounds.

The investigation of characteristics and structure of natural vegetable fibers (NVF) has indicated that the NVF composites possess superior mechanical characteristics with a low specific mass. The inadequate adhesion, its poor wettability, as well as the high level of moisture absorption by the fiber between the polymer matrix and untreated fibers, result in debonding. A surface modification of the fibers is necessary for the fabrication of composites with superb mechanical characteristics. Polymer composite characteristics are explained with regard to the chemical and physical NVF modification techniques such as graft copolymerization or plasma treatment. Depending on the resin, the tensile strength and Young's modulus are enhanced up to $50 \%$ by a coupling agent including stearin acid or silanes [59].

\subsection{Basalt fibers}

The special feature of glass fibers among other fibers used in FRPs is their high sensitivity to surface damage and alkaline conditions [60,61]. Carbon fiber is chemically neutral and hard and has disadvantages such as high cost and anisotropy. Recently, melted basalt has been used for the mass production of spun basalt fibers. Researches have shown that these fibers have comparable elasticity modulus, tensile strength, and alkali strength compared to E-glass fibers, and excellent surface shear strength $[62,63]$. It was shown 


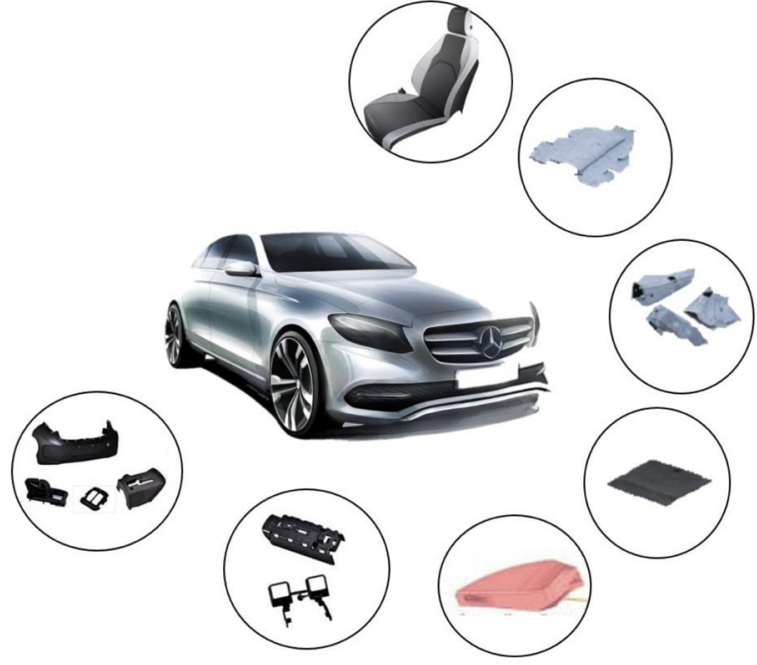

Fig. 3. Components of Mercedes E-Class produced by using natural fiber composites.

in the literature that Young's modulus of the basalt woven twill-reinforced epoxy composite can be considered comparably to that of the corresponding reinforced glass-epoxy composite with a twill weave of closely identical structure (GE-443). It is also shown that there are no considerable differences between composites of BGF 443 fabric-reinforced basalt epoxy and corresponding glass epoxy in terms of compressive, flexural, shear, and tensile strength. When using these materials in the transportation industry, one should pay attention to the composites' mechanical properties produced and be aware of the durability of the materials in different environments $[63,64]$.

\section{Mechanical properties of FRP composites}

The mechanical behavior of a fiber-reinforced composite depends on several factors, which can include fiber modulus, strength, matrix strength, chemical stability, and interface bonding of fiber/matrix for active stress transfer [65-67]. Mechanical and physical properties of natural fibers are dependent on cellulose amount (proportionately influencing tensile strength), lignin amount (proportionately has effects on hardness), fiber's angle of helix axis (adversely impacting tensile strength), and the amounts of hemicelluloses, waxes, water content, pectin, and the elementary cell geometry $[25,68]$.

The type of fibers can significantly affect the performance of NFCs. For instance, base fibers have high flexural strength and leaf fibers have very good impact properties [69]. Therefore, in order to achieve the best results, it is very crucial to understand the shapes and properties of fibers [70-72].

\subsection{Tensile strength}

Synthetic or natural fibers have significantly higher tensile strength compared to polymers. As a result, the tensile strength of polymer composites reinforced with fibers is much higher than polymer. Accordingly, the composite strength increases with increasing fiber content [73]. However, in some cases, the composites' strength does not follow this rule $[5,74]$.

A similar level of the tensile strength (at some low strength level) can be obtained for reinforced composite with glass fiber and NFRPCs. However, the amount of reinforcement rendering the same tensile strength is different. For instance, the required content for glass fiber is $12 \mathrm{wt} . \%$, and for aspen, kenaf, abaca, and pineapple fiber is $38 \mathrm{wt} . \%$, $38 \mathrm{wt} . \%, 35 \mathrm{wt} . \%$, and $15 \mathrm{wt} . \%$, respectively. Accordingly, there are limitations for obtaining the required tensile strength as there are limita-
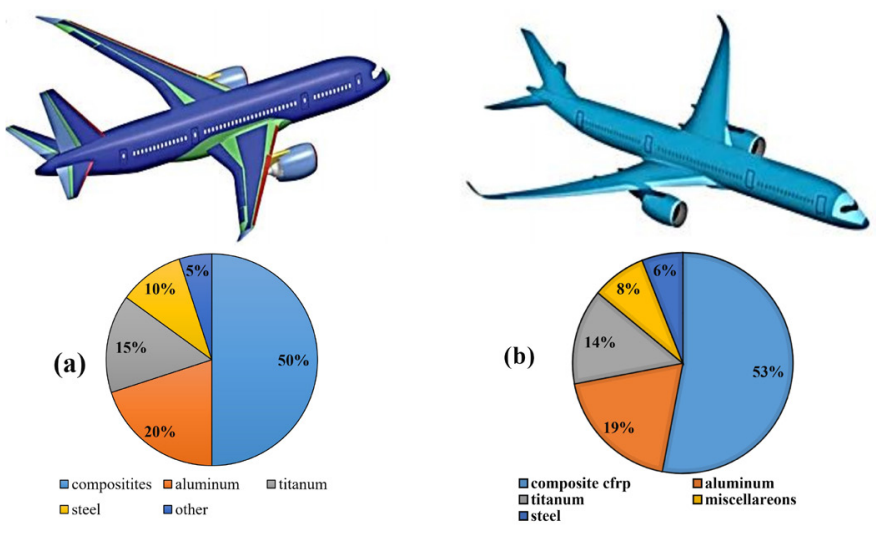

Fig. 4. Material composition of (a) Boeing Dreamliner and (b) airbus $350 \times$ wb.

tions in the content of natural fibers in the composition. However, some studies show different results. For example, a study by Müller et al. [74] showed that PP composites with almost the same tensile strength can be obtained using glass or flax fibers. The results of their study showed that by the incorporation of $30 \mathrm{wt} \%$ glass fibers and $33 \mathrm{wt} \%$ linen fibers, a tensile strength of $28 \mathrm{MPa}$ can be achieved. Because NFRPCs are much lighter than SFRPCs, therefore, the SFRPCs' specific gravity is more than that of NFRPCs. As a result, NFRPCs can be a better choice over SFRPCs when considering the weight and lightness of the final material. However, their mechanical strength is much lower than SFRPCs [75, 76].

\subsection{Young's modulus}

It is known from the research that the modulus of natural fiber decreases with an increase in its diameter. The influence of fiber loading on mechanical characteristics is of paramount importance to studies. Joseph et al. [77] made matrix ductile by adding fibers. They indicated that Young's modulus and tensile strength were enhanced by increasing fiber loading for a composite of banana/phenol formaldehyde (PF). Lee et al. [78] evaluated natural fiber of jute and kenaf reinforced polypropylene compositions with fiber weight fraction changing from $10 \%$ to $70 \%$ in the step of $10 \%$. It was found that the modulus and tensile strength of both jute and kenaf fiber reinforced compositions were enhanced by growing fiber loading so that the maximum value was achieved before falling back at higher fiber weight fraction.

The Young's modulus and mechanical and physical properties of sisal fiber are compared to other synthetic and natural fibers, exhibited in Table 3. According to Table 3, sisal fibers' specific strength and modulus are at the level of glass fibers. Fiber orientation, weight (wt\%), length, and volume fraction $\left(\mathrm{V}_{\mathrm{f}}\right)$ are all factors affecting the mechanical and physical properties of sisal fibers-reinforced polymer composites. Sisal fibers come in many forms, some of which are: short randomly oriented, unidirectional fibers, weave (mat, twill, and plain forms), and varied orientations (0-, 90-, and 45-degree plies, etc.). The tensile strength of sisal-epoxy composites is half of the glass-epoxy composites and their specific strength is comparable to reinforced-polymer composites with glass fibers. In addition, the tensile modulus of the reinforced epoxy composites with unidirectional sisal fiber is equal to $8.5 \mathrm{GPa}$. Thus, due to the properties of sisal fiber-based polymer composites, developed engineering structures, high-quality consumer goods, as well as, affordable housing can be built [74]. Satyanarayana et al. studied the mechanical properties of reinforced polyester composites with chopped sisal fiber. The fabrication of the composites was conducted by hand layup fol- 
Table 3.

The Young's modulus, mechanical and physical properties of sisal fiber and other synthetic and natural fibers

\begin{tabular}{cccc}
\hline Fibers & $\begin{array}{c}\text { Density } \\
\left(\mathbf{g} / \mathbf{c m}^{3}\right)\end{array}$ & $\begin{array}{c}\text { Young's } \\
\text { modulus }\end{array}$ & $\begin{array}{c}\text { Tensile } \\
\text { Strength (MPa) }\end{array}$ \\
\hline Carbon & 1.4 & $230-240$ & 4000 \\
Jute & $1.3-1.46$ & $10-30$ & $393-800$ \\
Sisal & $1.33-1.5$ & $9.0-38.0$ & $400-700$ \\
E-glass & 2.55 & 71 & 3400 \\
Harakeke & 1.3 & $11-25$ & $440-990$ \\
Coir & 1.2 & $4.0-6.0$ & $175-220$ \\
Vokka & 0.00081 & 15.85 & 549 \\
Oil Palm Empty & $0.7-1.55$ & 3.2 & 248 \\
Fruit Bunch & $0.6-1.1$ & $11-32$ & $140-800$ \\
Bamboo & $1.2-1.24$ & 53 & $295-930$ \\
Kenaf & & &
\end{tabular}

lowed by compression molding. The results of the study clarified that the specific modulus of these composites is very close to reinforced polyester composites with glass fibers [79].

Araujo et al. [21] studied the mechanical behavior of reinforced polyester matrix composites with virgin/waste GF at different fiber weight content of $20,30,40,50$, and $60 \%$. The reinforced-polyester composite with virgin GF possessed a higher modulus and tensile strength at $40 \%$ $\mathrm{w} \%$. Iba et al. [80] studied the mechanical characteristics of reinforced epoxy composites with fiber volume fraction from 0.25 to 0.45 , and three diameters of fibers $(18,37,50 \mathrm{~mm})$. Careful examination of the curve shows that the tensile strength and longitudinal Young's modulus of the composites increase with enhancing fiber volume fraction and the average strength increases with increasing fiber diameter. Godara et al. [45] surveyed the expandable behavior of epoxy composite reinforced with various orientations of GF woven fibers, e,g, 45 and 0/90. The stress-strain curve showed the strong dependency of the tensile strength on the alignment of the fibers to the external load, in which 0/90 laminate composites showed low strain failure $(1.65 \%)$, the highest failure strength (355MPa), and low ductility 45 .

\subsection{Flexural strength}

In recent years, the focus of some research has been on the fiber-reinforced composite materials' flexural strength [81]. For instance, Aramid et al. [82], investigated the mechanical characteristics of GF-reinforced polyunsaturated composite with various fibers volume fractions $(5,10,15,20,25$, and $30 \%)$. According to the results of their study, flexural strength increased with the increment of GF volume fraction, and also the maximum flexural properties were observed at GF with a $30 \%$ volume fraction. Husic et al. [83] also studied the mechanical behavior of reinforced polyurethane composites with untreated E-glass for two polyurethanes such as petrochemical polyol Jeffol and soypolyol resin. According to the results of their study, the composite based on petrochemical polyol Jeffol showed higher shear, tensile, and flexural strength between layers compared to soypolyol-based composites. This is because crosslinking densities are low in soypolyol-based composites and there are side-hanging chains in their matrix. Of course, the interlayer shear strength is the same for both resin composites. Some studies have examined the flexural characteristics of reinforced polyester matrix composites with E-GF by adding different carbon nano filler (CNF) weight percentages; for example the study of Hossain et al. [84] in 2011. According to the results of this study and by examining the stress-strain curve, the maximum mechanical properties were obtained in $0.2 \%$ by weight of CNF-filled composite. This was owing to the enhancement in compressive strength and modulus, further interfacial interaction, and high dispersion among matrix and fiber.
Patnaik et al. [85] studied the mechanical action of reinforced epoxy composites by randomly oriented E-GF, filled with particulates such as pine bark dust, $\mathrm{SiC}$, and $\mathrm{Al}_{2} \mathrm{O}_{3}$ and the various prepared specimen compositions like GF (50 wt \%)+ epoxy (40 wt $\%)+\mathrm{SiC}(10 \mathrm{wt} \%)$, GF $(50 \mathrm{wt} \%)+$ epoxy $(40 \mathrm{wt} \%)+$ pine bark dust $(10 \mathrm{wt} \%)$, GF (50 wt $\%)$ + epoxy $(40 \mathrm{wt} \%)$ +alumina $(10 \mathrm{wt} \%)$, and GF (50 wt $\%)+$ epoxy (50 $\mathrm{wt} \%)$. According to their study, the epoxy $+\mathrm{GF}$ owned higher flexural strength (368MPa) compared to other compositions. The results of flexural strength of a number of polymer-based composites with natural and synthetic fibers are gathered in Table 4.

\section{Application of FRP composites in the transportation industry}

Composites have found new applications in various industries including aerospace, automotive, and marine industries. Among all different composites, FRPs have become very popular because of their many advantages over plastics or metals, such as tailored substance properties, specific rigidity, corrosion, fatigue resistance, etc. According to studies, in the next ten years, we will see a 10 to 15 percent increase in the use of these composites every year, especially FRPs [40, 44].

Polymer composites, due to their many advantages, including low weight, reduce fatigue strength in clamps, and the number of parts, are being used in many industries, including the construction of rudders, elevators, fuselages, landing gear doors in the aircraft industry [79]. An important parameter in the degradation of polymer composites used in the marine industry is water absorption, and as a result, polyester matrix-based composites are widely used in this industry due to their properties [94]. These resins have found many applications in the mentioned cases due to their chemical/corrosion resistance properties, low shrinkage during curing, processing capability in different conditions, and high level of cross-connection of epoxy resin networks $[115,116]$.

In addition, GF reinforced composite wadding is used in the marine and plumbing industries. Features that make these materials suitable for use in the mentioned industries are high environmental resistance, better damage tolerance for impact loading, special strength, and high hardness. Natural fibers, on the other hand, have other properties that have created different uses for them. These fibers have low density and acceptable special properties and are therefore used in the automotive and transportation industries [80, 117, 118].

\subsection{Automotive industry}

One of the industries in which composites have found many applications is the automotive industry. In this industry, electric propulsion, limited energy source due to relatively low battery capacity, and low excitation of power traction are things that should be considered when using composites. Due to their high strength and weight, these composites are used in the design and construction of frames and car bodies in which lightweight is needed [54].

In the automotive industry, composite is used in the structure of the frame of the cars because of the complex characteristics of the car [19]. However, due to the high price of these composites, their use is not very common in this industry [19, 119-121]. FRP composites are lighter than aluminum-based materials. The basic properties of aluminum, FRP graphite, carbon FRP (CRFP), high tensile (HT) CFRP, and high modulus (HM) CFRP are shown in Table 5. The unit expense demonstrates raw substance and construction costs, like extruded aluminum or pultruded FRP. The price of FRP composites is higher than aluminum and especially CFRP composite is the most expensive material. However, it also has advantages, including the fact that the weight resistance of FRP composite is higher than aluminum. At the same weight, the composite 
Table 4.

Flexural strength of some polymer-based composites with natural and synthetic fibers

\begin{tabular}{|c|c|c|c|c|c|}
\hline Fiber & $\begin{array}{l}\text { Flexural strength } \\
(\mathrm{MPa})\end{array}$ & Young's modulus (GPa) & $\begin{array}{c}\text { Tensile Strength } \\
(\mathrm{MPa})\end{array}$ & Equipment's Used & Ref. \\
\hline Abaca & - & $6.2-20$ & $400-980$ & - & [86] \\
\hline Alfa & - & 22 & 35 & - & [87] \\
\hline Bamboo & 32 & $11-32$ & $140-800$ & UTM & [88-90] \\
\hline Banana & 76.53 & 17.85 & 600 & UTM & [91-93] \\
\hline Coconut & 58 & 2.50 & 500 & UTM & {$[94,95]$} \\
\hline Coir & 6 & $4-6$ & 175 & UTM & {$[26,96]$} \\
\hline Cotton & 43.3 & 12 & 400 & UTM & [97] \\
\hline Flax & 165 & $60-80$ & $800-1500$ & - & [98] \\
\hline fique & - & $8-12$ & 200 & UTM & [99] \\
\hline Hemp & - & 70 & $550-900$ & - & $\begin{array}{c}{[88,100,} \\
101]\end{array}$ \\
\hline Harakeke & 225 & 32.09 & 778 & UTM & {$[102]$} \\
\hline Jute & 45 & 8.78 & $320-800$ & UTM & $\begin{array}{c}{[88,103-} \\
105]\end{array}$ \\
\hline knave & 74 & 53 & 930 & UTM & [106] \\
\hline Palm & 24.44 & 2.75 & 377 & UTM & [107] \\
\hline Piassava & - & $1.07-4.59$ & $134-143$ & - & [108] \\
\hline pineapple & - & $34.5-84.5$ & $413-1627$ & UTM & [109-111] \\
\hline Ramie & - & 44 & 500 & - & [112] \\
\hline sisal & 288.6 & 38 & $600-700$ & UTM & {$[18,113]$} \\
\hline Wool & - & $2.3-3.4$ & $120-174$ & - & {$[46,114]$} \\
\hline
\end{tabular}

could demonstrate a better strength to bear the loading. At the National Composite Center (NCC) of Japan in the automotive industry, the CFRP composite has replaced aluminum alloys in all chassis components [122] resulting in $10 \%$ vehicle weight reduction with the same verified rigidity. Because of their high strength, composites are used in applications such as crash management structures, composite frame rails, and suspensions systems. The structure of FRP composites is such that a complex shape can be easily created. The complex shape of the car body increases aesthetics, greatly reduces drag coefficient, and increases aerodynamic performance [122]. When the car uses light structures such as composite structures, it causes less traction to accelerate the automobile in low-speed situations. The electric car developments require energy saving and light-weight. Adding carbon fibers renders the superior efficient polymers and the characteristics are in comparison with the light alloys of metals [54].

Smart and BASF (Germany) have jointly designed and built a vehicle that is very energy efficient, lightweight, and temperature adjustable. Design and manufacturing of lightweight parts have been one of the commitments of BASF in the automotive industry in the last 10 years. In the construction of electric vehicles, light weight and energy-saving are two very important features. BASF upgrades their vehicles by making various parts, including the chassis and exterior of the car using Baxxodur ${ }^{\circledR}$ carbon fiber-reinforced epoxy systems. When carbon fibers are added to composites, the performance of polymers increases, and, as a result, their performance is similar to light metal alloys.

Another design for the Smart ForVision is the usage of polymer wheel rim for mass production. The polymer wheel rim is built of the innovative efficient material called Ultramid $®$ Structure. The product is polyamide matrix reinforced with long glass fibers, which features great thermal and chemical stability, dynamic strength, well toughness, and middle durability. Polymer wheel rims are lightweight and they weigh 3 kilograms (7 pounds) lighter than a metal alloy. As a result, it saves 12 kilograms (26 pounds) per car. Consequently, each car consumes less fuel due to its light weight and will be more environmentally friendly. The Smart Forvision saves 0.05 liters ( 0.01 gallons) of fuel per 100 kilometers (62 miles) and emits less $\mathrm{CO}_{2}$ per kilometer ( 0.003 pounds per mile) [123].

Three companies in South Korea have co-produced composites on a large scale. LG Hansys, Hyundai Motor, and Shinhan Mold have launched an innovative battery module. Their company's product is a carbon fiber-reinforced polymer component in an electric vehicle. This piece is made without any metal reinforcements. Use of this substance has reduced weight by up to $26 \%$ (from 35 to $24 \mathrm{~kg}$ ). In addition, this material has other advantages such as no need for anti-corrosion paint, better charge maintenance, cost reduction, improvement in driving performance due to weight loss, and excellent recyclability [124, 125].

Polyamides improve the transfer of large shear stresses from the matrix to the glass fibers by bonding in the matrix-glass fibers, resulting in high mechanical properties of the composite. These composites are less expensive than metal alloy-based parts because the process requires only one tool to perform complete injection molding. Until now, polyamide-based composite sheets have been used for the hybrid front end of the Audi A8 which is produced by Bond-Laminates $\mathrm{GmbH}$ from the polymer under the name Durethan ${ }^{\circledR}$ BKV 30 H2.0 EF. The company Asahi Kasei Plastics, North America Inc. has produced a material called Thermylene ${ }^{\circledR}$ which is equivalent to LGFPP (Long-Glass Fibre-Rein- 
Table 5.

Comparison of natural fiber properties with carbon and glass fibers [134-136]

\begin{tabular}{cccc}
\hline farbon & $\begin{array}{c}\text { Glass fibers } \\
\text { fibers }\end{array}$ & $\begin{array}{c}\text { Natural } \\
\text { fibers }\end{array}$ \\
\hline Easy to dispose & No & No & Yes \\
$\begin{array}{c}\text { Abrasion to } \\
\text { machinery }\end{array}$ & Less & Yes & No \\
Health Hazards & Yes & Yes & No \\
Biodegradability & No & No & Yes \\
CO2 neutral & No & No & Yes \\
Energy consumption & High & High & Low \\
Recyclability & Difficult & Difficult & Yes \\
Renewability & No & No & Yes \\
& Remarkably & Low but more & \\
Coat & than natural & Low \\
& Equitant to & Double of & \\
nensity & natural ones & natural ones & Low \\
\hline
\end{tabular}

forced-Polypropylene). The advantages of these materials include their excellent mechanical properties and a $20 \%$ reduction in costs compared to other materials [126]. These materials are characterized by their relatively high hardness and longitudinal and transverse stiffness in a

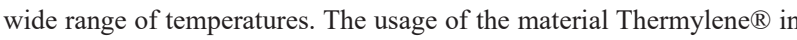
automotive crafts includes bumpers, luggage racks, and modules of gas/ brake/clutch.

Synthetic fibers also have disadvantages; they are expensive (except glass), require high energy to produce, and are not environmentally friendly. As a result, these fibers must be recycled after use to cause less damage to the environment. Therefore, to reduce the damage to the environment, costs, and energy consumption of production, the use of natural fibers has been introduced as an alternative to synthetic fibers. In recent years, NFRPs have attracted the attention of many researchers and manufacturers [127, 128]. Natural fibers such as flax, hemp, jute, and sisal are generally used as amplification in polymer composites owing to their favorable properties and easy availability. Composites made of natural fibers are much lighter than composites made of synthetic fibers due to their low density. The density of natural fibers is between 1.2 and $1.6 \mathrm{~g} \mathrm{/} \mathrm{cm}^{3}$ and glass fibers are between 2.16 and 2.16. 2.68 grams per cubic centimeter. For example, generating a flax fiber mattress consumes about $82 \%$ less energy than producing a glass fiber mattress. Composites made from natural fibers have features such as low cost, renewable, carbon-neutral, non-abrasive quality, limited health hazards, quality of sound, heat and electrical insulation, and ease of disposal [10]. But, composites with natural fibers also have disadvantages such as high humidity, low fire resistance, poor surface adhesion, poor resistance to microbial attack, and the need to use low processing temperatures. In the automotive and transportation industry, these composites have found many applications due to their low density and high acceptable special properties. For example, polymer composites reinforced with linen, jute, kenaf, and sisal fibers are used to manufacture the inner and outer panels of the car body. Abaka fiber reinforced polypropylene composite has found applications in the automotive and transportation industries due to low cost, accessibility, high flexural and tensile strength, fine abrasion and acoustic resistance, relatively better mold resistance, and very good UV resistance [5].

Sisal fiber-based polymer composites have gained many applications in many industries, including the aerospace and aircraft industries. Studies by previous researchers have shown that these composites can be utilized in engine covers, door panels, helmet shelves, pack trays, sun visors, seat backs, and exterior or underground paneling in cars. Sisal fiber can also be used in rope, carpet, mattress, etc., and other applications in the aircraft and automotive industries [26].
Flax, hemp, jute, hemp, and ramie are different types of bast fibers. Bast fibers have many applications in the automotive industry. They have high strength and low density and as a result, the weight of the final product is reduced. Wood fibers include two types of soft wood and hard wood. These fibers are extracted from trees $[129,130]$. These fibers are generally utilized in a mix with virgin or recycled plastics to generate wood-plastic composites. They have many applications like decking systems, railing, windows, and doors. Flax, hemp, jute, sisal, hemp, blueberries, abacus, wood, and certain plant residues such as rice are the most common natural fibers used as reinforcements in transportation. Linen is used in cars as the cover of doors and seats, floor panels, and disc brakes. The mechanical strength of hemp fibers and their Young's modulus is higher than other fibers. These fibers are used in door covers, floor panels, and car seat cover. The advantage of these fibers is that they are cheaper than other fibers. Jute fibers have properties such as great tensile strength and acceptable thermal/insulating properties. Their specific modulus is approximately equal to that of glass fibers. These fibers can tolerate temperatures up to $200{ }^{\circ} \mathrm{C}$ without any changes in properties. Other features include moisture tolerance and environmental friendliness. In the automotive industry, these fibers are used in the production of doors and roof panels.

Abaca/banana fiber comes from the evergreen banana plant and has very good tensile strength. Another application of Abaka fibers is in the production of car floor panels. Another type of fiber is the fiber that is obtained from the husk and outer shell of the coconut and is called Coir. The advantage of these fibers is that they are renewable. These fibers are also thick and coarse. The characteristics of these fibers include sea water resistance, heat tolerance, pest and fungi resistance, good acoustic resistance, and anti-wear. Coir fibers are found in helmets, bulletproof vests, car seats, and back cushions in the car, roof, postbox, yarn, rope, mattress, brush, sack, rug, and insulation panels [131-133].

NFRP composites are used extensively by German automakers, including Mercedes-Benz, DaimlerChrysler, Volkswagen, Audi, and BMW. Composites are also being used by a number of other automakers in recent years, including Peugeot, Renault, Opel, Volvo, Ford, and General Motors. Fibers such as wool, sisal, hemp, and flax are utilized in the components of the Mercedes-Benz E-Class. Recent Daimler models, including those in Class A, Class C, Class E, and S, have been strengthened with coconut, sisal, hemp, and flax reinforced fibers. Although engineering plastics are rarely employed in the fabrication of NFRP composite materials, virgin plastics or thermostats are frequently used. Fig. 3 shows various components of Mercedes E-Class produced by using natural fiber composites. According to BMW, in 2004, the company used about 10,000 tons of natural fibers, including linen, sisal, cotton, and wood fibers, to build its vehicles [48, 59, 122]. Table 6 lists some automotive parts that are produced with the use of natural fibers in the automotive industry.

Choosing the correct material for the car's equipment is quite critical and crucial. You can get little damage in an accident, cost-effectiveness, and proper weight by selecting the right raw material. Fuel consumption decreases when a vehicle's mass is reduced, which leads to less $\mathrm{CO}_{2}$ emissions into the atmosphere. The cost of raw materials is another key consideration for car producers. Carbon fiber, for example, despite the decreasing weight, raises the price. The impact of energy absorption capabilities of raw materials is also key considerations when designing a vehicle, as it ensures the safety of its occupants during car accidents. Natural fibers are chosen based on their proximity to the customer's location (geographical proximity). For example, jute, and kenaf are commonly used in India and Asia, while hemp or flax is commonly used in Europe. The raw material is ramie or sisal in South America. A car's weight is reduced and its efficiency increases when NFRP is employed. As a result, the car is more safe and secure. Finally, natural fiber composites will reduce vehicle weight and cost by $30 \%$ and $20 \%$, respective- 
Table 6.

Natural fibers in automotive parts [56, 137, 139, 140]

\begin{tabular}{|c|c|c|c|}
\hline Manufacturers & Model & Applications & Natural fiber \\
\hline Volvo Mitsubishi & $\mathrm{V} 70, \mathrm{C} 70$ & $\begin{array}{l}\text { Instrument panels, door panels, } \\
\text { cargo area floors, cargo floor mats, } \\
\text { seat cushions. }\end{array}$ & - \\
\hline Fiat & $\begin{array}{c}\text { Punto, Brava, AlfaRomeo 146, } \\
156,159\end{array}$ & Door panels & - \\
\hline Lotus Peugeot & Eco Elsie 406 & $\begin{array}{l}\text { Packaging trays, seat backs, seats } \\
\text { front and rare door panels, interior } \\
\text { mats, body panels. }\end{array}$ & Sisal, hemp \\
\hline Opel & Vectra, Astra, Zafira & $\begin{array}{l}\text { Instrumental panels, head liner } \\
\text { panels, door panels. }\end{array}$ & Kenaf, flax \\
\hline General motors & $\begin{array}{c}\text { Cadillac DeVille, Chevy Trailblazer, } \\
\text { Chevy Impala, GMC Envoy Vectra, } \\
\text { Astra, Zafira. }\end{array}$ & $\begin{array}{l}\text { Trim, door panels, noise insulation, } \\
\text { cargo area floor mats, seat backs. }\end{array}$ & Hemp, kenaf, wood, flax, cotton \\
\hline Toyota & Raum, brevis, harrier, celsior & $\begin{array}{c}\text { Luggage compartments, seat back } \\
\text { and door panels, spare tire cover, } \\
\text { floor mats. }\end{array}$ & $\begin{array}{l}\text { Bamboo, sugarcane, } \\
\text { kenaf }\end{array}$ \\
\hline Ford & Mondeu, Focus & $\begin{array}{l}\text { Door inserts, floor trays, boot liners, } \\
\text { door panels. }\end{array}$ & Castor, wheat, kenaf \\
\hline Volksvagen & Golf, Passat, Bora, A4 & $\begin{array}{l}\text { Boot finish lid panels, boot liners, } \\
\text { door panels, seat backs. }\end{array}$ & Sisal, flax \\
\hline Audi & $\mathrm{A} 2, \mathrm{~A} 3, \mathrm{~A} 4, \mathrm{~A} 6, \mathrm{~A} 8, \mathrm{~A} 4$ avant,Roadster & $\begin{array}{l}\text { Spare tire liner, side door panels, } \\
\text { boot liners, back door panels, seat } \\
\text { backs. }\end{array}$ & Sisal, flax \\
\hline BMW & 3,5 , and 7 series & $\begin{array}{l}\text { Noise insulation panels, headliner } \\
\text { panel, seat backs, boot lining, door } \\
\text { panels. }\end{array}$ & Hemp, wood, cotton, sisal, flax \\
\hline Dimlar Chysler & $\mathrm{A}, \mathrm{C}, \mathrm{E}$, and S Class & $\begin{array}{l}\text { Seat back rests, boot linings, pillar } \\
\text { cover panels, dashboards, trunk } \\
\text { panels, floor panels, door panels. }\end{array}$ & $\begin{array}{l}\text { Cotton, banana, wood, coir, sisal, } \\
\text { flax }\end{array}$ \\
\hline
\end{tabular}

ly. Dashboards, headboards, and doors in Europe are made from natural fibers such as sisal, jute, hemp, and flax to minimize weight, cost, and $\mathrm{CO}_{2}$ emissions $[137,138]$.

\subsection{Aerospace industry}

Today's aerospace industry relies heavily on non-renewable and synthetic resources for its basic materials. Carbon fiber composites and metals like fiberglass, titanium, and aluminum are used to make various aircraft parts. Both Boeing 787 Dreamliner and Airbus 350 XWB aircraft have employed composite materials to build their stabilizers, wings, turbine housing, and bodies (Fig. 4a and 4b, respectively). The use of composites in the fuselage will result in a reduction in overall weight, as well as an increase in durability, reduced noise, and improved passenger comfort. Due to their ease of production in complex geometries, acceptable hardness, and excellent specific strength, composite materials are employed in the aviation sector to create and produce low-weight structural designs. Using composite materials in aerospace has resulted in airplanes with lower fuel consumption in recent years. Composite materials are commonly utilized in aircraft cabin interiors because of their excellent strength and durability. Wall panels, roof, toilets, chairs, flooring, and cabin partitions as well as storage bins and galleys are all made with these materials. Increased strength and reduced weight can be achieved through the use of composite materials in mechanical designs. Composite materials make up $25 \%$ of the weight of Airbus 380 passenger jets and $50 \%$ of the weight of Boeing $787 \mathrm{~s}$. As a result of Boeing's weight decrease, fuel consumption has been reduced by $20 \%$. This has helped to alleviate the energy crisis and reduce air pollution [22].

Maneuverability, cargo capacity, and fuel efficiency have all improved because of the lightweight and great mechanical strength of these materials. American Airlines Fleet is a good case in point. By lowering the weight of each aircraft by one pound, the business has saved around
11,000 gallons of fuel. Boeing's B-787 Dreamliner is another example. In the aerospace business, it is recognized as a leader because of the aircraft's superior materials and construction. Compared to similar aircraft, the fuselage's weight has been decreased by $50 \%$ due to the use of composite materials in many of its components. On this aircraft, that equates to an 80 percent reduction in PMC. Carbon fiber reinforced sandwich sheets are used on the Boeing B-787 Dreamliner. A limited number of aircraft components, simple-to-produce complicated structural shapes, low operating cost, high rigidity, and high strength are some of the advantages of this construction. It also has good corrosion resistance and a short assembly time. Additionally, Hexcel's HexMC epoxy carbon composite is utilized in the Boeing 787. (USA). Mechanical strength and stiffness, as well as the ability to make sandwiches of various forms, make this aircraft a viable choice for transport. There are many brackets, fittings, and window frames in Dreamliner that use HexMC as an example of HexMC in the design [141]

Research, development, and new technologies in the production of Russian aircraft are the focus of AeroComposit (Russia-Moscow). Composites made of carbon fiber for civilian airplanes have been developed by the business. New and improved resins and carbon fibers can be used together in this industry. For Patria Aerostructures Oy (Patria), Finland is the source of all raw materials needed. The A400M VTP tip, the A380 wing spoiler, and the NH90 helicopter fuselage are all currently in development. Using T700 carbon fiber reinforcement and M21 prepreg resin systems in a honeycomb configuration, the material structure can be described as a composite sandwich box. In the aerospace sector, Victrex Europa $\mathrm{GmbH}$ is an excellent metal alternative and superior alternative to conventionally utilized metal alloys. In the polyaryl ether of ketones (PAEK), VICTREX ${ }^{\circledR}$ PEEK (Polyester Ketone) is an aromatic polymer that is semi-crystalline and linear. In terms of mechanical strength and dimensional stability, VICTREX® PEEK polymer compounds are com- 
parable to metal alloys. This polymer has the advantage of being able to endure temperatures and chemical conditions that are relatively high. Among other things, this polymer is resistant to corrosion and abrasion, and it also has good resistance to many hostile chemicals. Yet the greatest benefit of this polymer is that it's inexpensive. High modulus carbon fiber, crushed glass, and carbon fiber are employed as reinforcement in VICTREX®PEEK-based composites [47, 48].

Due to their reduced weight and greater biodegradability, natural fibers have been increasingly popular in recent years. Minimizing fuel consumption, increasing cargo capacity, reducing weight, and boosting mobility are all critical considerations in aircraft design. Because NFRPs cut fuel consumption and greenhouse gas emissions, they meet all of the requirements and regulations for airplane construction. Aerodynamic efficiency is improved due to their high strength and rigidity, as well as their acceptable fatigue and corrosion qualities. NFRP composite is used in a variety of aircraft components, including the propeller system, side walls, and cabin equipment. These pieces, for example, can include a total of more than 200 parts in the plane $[142,143]$.

The European Union encourages the use of NFRP composites in aircraft construction in Europe. A project called Eco-Compass has also been created by the EU. The goal of the project is to create bio-based and recycled composites for use in the aviation industry that are environmentally beneficial. Recycled carbon fiber and natural fiber-reinforced polymers will be used to replace carbon and glass-reinforced polymers in aircraft secondary structures and interior applications. The tensile strength and flame retardant qualities of NFRP composites are improved by using flax and ramie fibers. In order to obtain both great performance and low weight, epoxy resins are frequently mixed with carbon fiber or natural fibers. Flax/epoxy sandwich composites with flax fabrics flame retardants that do not include halogens are utilized to produce the Boeing 737 side panels.

\subsection{Maritime transportation}

Composites have been increasingly popular in the marine industry in recent years. They're lighter, easier to weld, and stronger than steel and aluminum alloys. Composites are widely employed in the marine industry for a wide range of applications, including pumps, valves, heat exchangers, propellers, decks, pipelines, ducts, waterproof doors, and walls. Carbon-glazed polymer-reinforced polymer composites are employed in shipbuilding and boating sectors because they are light and resistant to shock waves. Because they are made of light FRP composites, vehicles use less gasoline. Waterproofness and corrosion resistance are two more benefits of FRP. The ability of carbon composites to absorb electromagnetic waves is crucial in ship hull design and construction. Carbon fiber reinforced-polymer resins such as phenolic, polyester, vinyl ester, or epoxy is used in boat construction. Revolver 42 speedboats (weighing 7,500 kg) and the Vestas Sailrocket 2 are two examples of boats made using this technology. Sailboat Revolver 42 set a new record for speed, averaging more than 65 knots per hour during testing. Other drawbacks of these composites include their low recyclability, inability to be repaired, lack of environmental friendliness, and high cost.

FRP composite structures require heat-resistant polymer resins including vinyl ester, polyester, and epoxy, which are difficult to recycle. There has been a recent uptick in the use of thermoplastics in maritime constructions, such as PBT, PET, PP, and PA. It is possible to recycle these thermoplastics.

Boat building has led to the idea that natural fibers should be employed in composites. Sails, nets, and ropes have traditionally been made from natural fibers. Because natural fibers are less expensive, they are often preferred over synthetic ones. Their impact on the environment is negligible as well. The absorption of moisture by natural fibers is a serious issue in the shipping industry. Paraffin wax or flaxseed oil were once used to waterproof natural fiber sail material to alleviate this problem. Moisture absorption is the biggest issue when employing NFRP composites. The poor surface adherence of the natural fibers to the polymer resin matrix is another issue. This issue has been investigated in an attempt to resolve it. For example, natural fibers can be chemically treated to improve their adhesion to a polymer matrix, or you can create hybrid composites from NFRP and synthetic fibers that are stacked [144]. Although natural fibers have their advantages, the shipbuilding industry prefers to employ glass and carbon fibers instead.

However, more research is required to determine whether natural fibers can be improved and used in maritime applications. For instance, the NavEcoMat project has been completed under this situation. Offshore construction businesses and materials research laboratories collaborated on this study. Using PLA and linen fibers, a composite material with qualities similar to those of glass or carbon composites was put to the test as part of this experiment. A Naskapi-style boat constructed of PLA sheets and flax fiber mats was created using the newly found technique. The "Araldite" racing boat prototype was the result of the second research. The epoxy matrix in this sample was strengthened with $50 \%$ of the linen fiber. Kayaks and canoes have also been made using biorosine flax fiber (EcoComp ${ }^{\circledR}$ UV-L). Basalt fibers have excellent mechanical properties and are environmentally friendly. As a result, yacht hulls and decks are constructed primarily from composite materials such as basalt and wood.

The Revolver 42 speedboat was built by Michael Peters Yacht Design and Milan-based H30 Studio. They were working on a high-speed boat. The boat is described by S. Bell and M. Arcuri as 'a vacuum-infused and bonded foam sandwich design'. Crystic ${ }^{\circledR}$ vinyl ester (VE) resins and a CorecellTM M-foam core reinforced with carbon fibers form the hull and deck of the boat. In addition to the foregoing, yachts are built with composite materials. They were designed and built by the Vestas Sailrocket team (Vestas R\&D, Isle of Wight) in the United Kingdom. After a record-breaking speed of 65.37 knots, an Australian yacht pilot named Paul Larson VSR 2 broke the speed record in Walvis Bay, Namibia in 2012. This boat's wing was constructed using carbon fiber. Pre-impregnated carbon fiber is used primarily for the wing skins, with a Nomex honeycomb core and polyester heat shrink film covering the rest of the structure [141].

Small boats, yachts, and boats have been proposed as alternatives to conventional polymers and composites because of environmental concerns, including waste disposal. Polyester and epoxy resins containing hybrid reinforcements, i.e. flax fibers with glass or carbon fibers, have been studied recently. The NavEcoMat project is a collaboration between boat manufacturers and materials research institutions to develop environmentally friendly materials for boats. Polylactic acid (PLA) and flax fibers are used in this study to create an environmentally acceptable polymer-based composite material. The Indian sailing vessel Naskapi is a good illustration of this in action. Glass or carbon-reinforced composite materials have the same mechanical qualities as a Nascopi canoe. Linen fiber mattresses and PLA thermoplastic layers make up this material. Kairos Inc. and Ifremer (France) collaborated on a joint initiative. All sandwich kernels, composites, and bio-based polymers that might be used in commercial boats were compiled as part of this effort. A wide range of reinforcements, including flax and hemp, hemp and jute, and cellulose and jute fibers, are included in this list [145]. When two boats of equivalent weight, reinforcing fiber content, and resin matrix were compared, the results were striking. The former is constructed from a glass/epoxy composite, whereas the latter is constructed from an epoxy composite reinforced with cellulose. At a temperature of $40^{\circ} \mathrm{C}$, the two boats were submerged in seawater for this experiment. The study's findings showed that the two boats had equal and equivalent performance and technical specs $[47,48]$.

Fiber-reinforced polymer composites have a usable life of 15 to 20 
years in most applications, but they have often kept their physical qualities for far longer periods [59].

\section{Conclusions}

In this review, the recent investigations on synthetic and natural fiber-reinforced polymers with a close focus on their mechanical properties have been discussed in order to evaluate their application in maritime, automotive, and aerospace. Fiber materials are employed in transportation because of their relatively high Young's modulus. Additionally, composites made of carbon fibers and polymers are both impacts and weight resistant. Also, they are used in the marine industry because of their excellent corrosion resistance. Since they consume less fuel and have better strength, composites are popular in the aviation industry. NFRP composites are one of the most recent additions. Using natural fiber rather than carbon or glass fiber is, of course, a feasible business option. Moreover, some components of automobiles are constructed using composite materials. However, their exorbitant cost may make them unaffordable in some cases. Advantages include the fact that the FRP composite's weight is lower than that metal counterparts. At the same weight, composites can demonstrate greater load-bearing capacity. There are several types of polymer matrices, including thermosetting resins and thermoplastic resins. The method of making thermoplastic resins includes conventional molding techniques including injection molding, vacuum forming, extrusion, rotational molding, and compression molding. However, to enhance the quality of the product, there are many significant challenges that should be considered in future investigations.

\section{REFERENCES}

[1] A.V. Oskouei, A. Jafari, M. Bazli, R. Ghahri, Effect of different retrofitting techniques on in-plane behavior of masonry wallettes, Construction and Building Materials 169 (2018) 578-590

[2] A.V. Oskouei, M.P. Kivi, H. Araghi, M. Bazli, Experimental study of the punching behavior of GFRP reinforced lightweight concrete footing, Materials and Structures 50(6) (2017) 1-14.

[3] M. Bazli, X.-L. Zhao, Y. Bai, R.S. Raman, S. Al-Saadi, A. Haque, Durability of pultruded GFRP tubes subjected to seawater sea sand concrete and seawater environments, Construction and Building Materials 245 (2020) 118399

[4] H. Ashrafi, M. Bazli, A. Jafari, T. Ozbakkaloglu, Tensile properties of GFRP laminates after exposure to elevated temperatures: Effect of fiber configuration, sample thickness, and time of exposure, Composite Structures 238 (2020) 111971. [5] H. Abral, J. Ariksa, M. Mahardika, D. Handayani, I. Aminah, N. Sandrawati, S. Sapuan, R. Ilyas, Highly transparent and antimicrobial PVA based bionanocomposites reinforced by ginger nanofiber, Polymer Testing 81 (2020) 106186.

[6] M. Bazli, H. Ashrafi, A.V. Oskouei, Effect of harsh environments on mechanical properties of GFRP pultruded profiles, Composites Part B: Engineering 99 (2016) 203-215

[7] I.M. Daniel, O. Ishai, I.M. Daniel, I. Daniel, Engineering mechanics of composite materials, Oxford university press New York2006.

[8] A. Jafari, A.V. Oskouei, M. Bazli, R. Ghahri, Effect of the FRP sheet's arrays and NSM FRP bars on in-plane behavior of URM walls, Journal of Building Engineering 20 (2018) 679-695.

[9] M. Bazli, X.-L. Zhao, A. Jafari, H. Ashrafi, R.S. Raman, Y. Bai, H. Khezrzadeh, Durability of glass-fibre-reinforced polymer composites under seawater and seasand concrete coupled with harsh outdoor environments, Advances in Structural Engineering 24(6) (2021) 1090-1109.

[10] M. Bazli, L. Bazli, R. Rahmani, S. Mansoor, M. Ahmadi, R. Pouriamanesh, Concrete filled FRP-PVC tubular columns used in the construction sector: A review, Journal of Composites and Compounds 2(4) (2020) 155-162.

[11] M. Bazli, X.-L. Zhao, Y. Bai, R.S. Raman, S. Al-Saadi, Bond-slip behaviour between FRP tubes and seawater sea sand concrete, Engineering Structures 197 (2019) 109421

[12] S. Alsubari, M. Zuhri, S. Sapuan, M. Ishak, R. Ilyas, M. Asyraf, Potential of natural fiber reinforced polymer composites in sandwich structures: A review on its mechanical properties, Polymers 13(3) (2021) 423.

[13] H. Ashrafi, M. Bazli, E.P. Najafabadi, A.V. Oskouei, The effect of mechanical and thermal properties of FRP bars on their tensile performance under elevated temperatures, Construction and building materials 157 (2017) 1001-1010.

[14] A. Jafari, H. Ashrafi, M. Bazli, T. Ozbakkaloglu, Effect of thermal cycles on mechanical response of pultruded glass fiber reinforced polymer profiles of different geometries, Composite Structures 223 (2019) 110959

[15] M. Bazli, H. Ashrafi, A.V. Oskouei, Experiments and probabilistic models of bond strength between GFRP bar and different types of concrete under aggressive environments, Construction and Building Materials 148 (2017) 429-443.

[16] M. Bazli, H. Ashrafi, A. Jafari, X.-L. Zhao, H. Gholipour, A.V. Oskouei, Effect of thickness and reinforcement configuration on flexural and impact behaviour of GFRP laminates after exposure to elevated temperatures, Composites Part B: Engineering 157 (2019) 76-99.

[17] J. Andersons, E. Spārnin̄̌s, R. Joffe, Stiffness and strength of flax fiber/polymer matrix composites, Polymer Composites 27(2) (2006) 221-229.

[18] V.K. Thakur, M.K. Thakur, R.K.J.I.J.o.P.A. Gupta, Characterization, Raw natural fiber-based polymer composites, 19(3) (2014) 256-271.

[19] T. Väisänen, A. Haapala, R. Lappalainen, L.J.W.M. Tomppo, Utilization of agricultural and forest industry waste and residues in natural fiber-polymer composites: A review, 54 (2016) 62-73

[20] F. Aramide, P. Atanda, O. Olorunniwo, Mechanical properties of a polyester fibre glass composite, International Journal of Composite Materials 2(6) (2012) $147-151$.

[21] E.M. Araújo, K.D. Araújo, O.D. Pereira, P.C. Ribeiro, T.J. de Melo, Fiberglass wastes/polyester resin composites: mechanical properties and water sorption, Polímeros 16 (2006) 332-335

[22] F. Arifurrahman, B.A. Budiman, M. Aziz, On the lightweight structural design for electric road and railway vehicles using fiber reinforced polymer composites-a review, International Journal of Sustainable Transportation Technology 1(1) (2018) 21-29

[23] A. Avci, H. Arikan, A. Akdemir, Fracture behavior of glass fiber reinforced polymer composite, Cement and Concrete Research 34(3) (2004) 429-434

[24] K. Begum, M. Islam, Natural fiber as a substitute to synthetic fiber in polymer composites: a review, Research Journal of Engineering Sciences 2278 (2013) 9472.

[25] F. Bello-Millán, T. Mäkelä, L. Parras, C. Del Pino, C. Ferrera, Experimental study on Ahmed's body drag coefficient for different yaw angles, Journal of Wind Engineering and Industrial Aerodynamics 157 (2016) 140-144

[26] U.M. Boopalan M, Jenyfer PJS, . A comparative study on the mechanical properties of jute and sisal fiber reinforced polymer composites, 4(4) (2012) 145 -

[27] F. Tanasă, M. Zănoagă, C.A. Teacă, M. Nechifor, A.J.P.C. Shahzad, Modified hemp fibers intended for fiber-reinforced polymer composites used in structural applications-A review. I. Methods of modification, 41(1) (2020) 5-31.

[28] T. Corbière-Nicollier, B.G. Laban, L. Lundquist, Y. Leterrier, J.-A. Månson, O. Jolliet, Life cycle assessment of biofibres replacing glass fibres as reinforcement in plastics, Resources, Conservation and recycling 33(4) (2001) 267-287. [29] L. Bazli, M. Barghamadi, S. Shafiee, M. Karrabi, M.H.R. Ghoreishy, Investigation of rheological, mechanical, and thermal properties of nanocomposites based on nitrile rubber-phenolic resin reinforced with nanographene, Journal of Applied Polymer Science (2021) 50906.

[30] L. Bazli, A. Khavandi, M.A. Boutorabi, M. Karrabi, Correlation between viscoelastic behavior and morphology of nanocomposites based on SR/EPDM blends compatibilized by maleic anhydride, Polymer 113 (2017) 156-166.

[31] L. Bazli, A. Khavandi, M.A. Boutorabi, M. Karrabi, Morphology and viscoelastic behavior of silicone rubber/EPDM/Cloisite 15A nanocomposites based on Maxwell model, Iranian Polymer Journal 25(11) (2016) 907-918

[32] A.J.M. Fariborz Sharifianjazi Amirhossein Moghanian, Jalalian, Synthesis and characterization of polymer matrix composites reinforced with sand particles in buildings and highways application, International Conference on Polymer in Construction, Iran University of Science and Technology, Tehran, Iran (2016).

[33] F.S. da Luz, F.d.C. Garcia Filho, M.T.G. Del-Rio, L.F.C. Nascimento, W.A. Pinheiro, S.N. Monteiro, Graphene-incorporated natural fiber polymer composites: A first overview, Polymers 12(7) (2020) 1601

[34] S. Erden, K. Sever, Y. Seki, M. Sarikanat, Enhancement of the mechanical properties of glass/polyester composites via matrix modification glass/polyester composite siloxane matrix modification, Fibers and polymers 11(5) (2010) 732737.

[35] P.J.P.E. Toensmeier, Slimming Down: Auto OEMs focus on lightweighting to meet regulatory standards, 68(7) (2012) 16-23.

[36] E.R. Fuchs, F.R. Field, R. Roth, R.E. Kirchain, Strategic materials selection in the automobile body: Economic opportunities for polymer composite design, Composites science and technology 68(9) (2008) 1989-2002 
[37] M. Bazli, Y.-L. Li, X.-L. Zhao, R.S. Raman, Y. Bai, S. Al-Saadi, A. Haque, Durability of seawater and sea sand concrete filled filament wound FRP tubes under seawater environments, Composites Part B: Engineering 202 (2020) 108409. [38] M. Bazli, M. Abolfazli, Mechanical Properties of Fibre Reinforced Polymers under Elevated Temperatures: An Overview, Polymers 12(11) (2020) 2600.

[39] M.M. Thwe, K. Liao, Effects of environmental aging on the mechanical properties of bamboo-glass fiber reinforced polymer matrix hybrid composites, Composites Part A: Applied Science and Manufacturing 33(1) (2002) 43-52.

[40] A.L. Naidu, D. Raghuveer, P. Suman, Studies on characterization and mechanical behavior of banana peel reinforced epoxy composites, Int J Sci Eng Res 4(6) (2013) 844-851.

[41] Y. Ruksakulpiwat, N. Suppakarn, W. Sutapun, W. Thomthong, Vetiver-polypropylene composites: physical and mechanical properties, Composites Part A: Applied Science and Manufacturing 38(2) (2007) 590-601

[42] A. Belaadi, A. Bezazi, M. Maache, F. Scarpa, Fatigue in sisal fiber reinforced polyester composites: hysteresis and energy dissipation, Procedia Engineering 74 (2014) 325-328.

[43] K. Srinivas, A.L. Naidu, M.R.J.I.J.o.P.E. Bahubalendruni, A review on chemical and mechanical properties of natural fiber reinforced polymer composites, 13(2) (2017) 189.

[44] I. Gajlewicz, M. Lenartowicz, Additives for plastics used in the automotive industry, PlastNews,(2’2013) (2013) 34-38.

[45] A. Godara, D. Raabe, Influence of fiber orientation on global mechanical behavior and mesoscale strain localization in a short glass-fiber-reinforced epoxy polymer composite during tensile deformation investigated using digital image correlation, Composites Science and technology 67(11-12) (2007) 2417-2427.

[46] N. Hameed, P. Sreekumar, B. Francis, W. Yang, S. Thomas, Morphology, dynamic mechanical and thermal studies on poly (styrene-co-acrylonitrile) modified epoxy resin/glass fibre composites, Composites Part A: Applied Science and Manufacturing 38(12) (2007) 2422-2432.

[47] A.G. Koniuszewska, J.W. Kaczmar, Application of Polymer Based Composite Materials in Transportation, Progress in Rubber, Plastics and Recycling Technology 32(1) (2016) 1-24 DOI: 10.1177/147776061603200101.

[48] M.K. Hossain, M.E. Hossain, M.V. Hosur, S. Jeelani, Flexural and compression response of woven E-glass/polyester-CNF nanophased composites, Composites Part A: Applied Science and Manufacturing 42(11) (2011) 1774-1782.

[49] H. Ashrafi, M. Bazli, A.V. Oskouei, Enhancement of bond characteristics of ribbed-surface GFRP bars with concrete by using carbon fiber mat anchorage, Construction and Building Materials 134 (2017) 507-519.

[50] M.H. Khaneghahi, E.P. Najafabadi, M. Bazli, A.V. Oskouei, X.-L. Zhao, The effect of elevated temperatures on the compressive section capacity of pultruded GFRP profiles, Construction and Building Materials 249 (2020) 118725.

[51] F. López, M. Martín, F. Alguacil, J.M. Rincón, T. Centeno, M. Romero, Thermolysis of fibreglass polyester composite and reutilisation of the glass fibre residue to obtain a glass-ceramic material, Journal of Analytical and Applied Pyrolysis 93 (2012) 104-112.

[52] R. Rana, R.J.M.T.P. Purohit, A Review on mechanical property of sisal glass fiber reinforced polymer composites, 4(2) (2017) 3466-3476.

[53] S. Samantaa, M. Muralidharb, Thingujam Jackson singhc, S, Sarkard, NERIST, Arunachal Pradesh, India (2015).

[54] B. Suddell, W. Evans, The increasing use and application of natural fiber composite materials within the automotive industry, Seventh Composite Conference on Woodfiber-Plastic Composites, 2003, pp. 7-14.

[55] R.A. Ilyas, S.M. Sapuan, R. Ibrahim, H. Abral, M. Ishak, E. Zainudin, M. Asrofi, M.S.N. Atikah, M.R.M. Huzaifah, A.M. Radzi, Sugar palm (Arenga pinnata (Wurmb.) Merr) cellulosic fibre hierarchy: a comprehensive approach from macro to nano scale, Journal of Materials Research and Technology 8(3) (2019) 2753-2766.

[56] D. Verma, S. Sharma, Green biocomposites: a prospective utilization in automobile industry, Green Biocomposites, Springer2017, pp. 167-191.

[57] K. Rohit, S. Dixit, A review-future aspect of natural fiber reinforced composite, Polymers from Renewable Resources 7(2) (2016) 43-59.

[58] R.D. Anandjiwala, S. Blouw, Composites from bast fibres-prospects and potential in the changing market environment, Journal of Natural Fibers 4(2) (2007) 91-109.

[59] Y.-H. Zhao, Y.-F. Zhang, S.-L. Bai, X.-W. Yuan, Carbon fibre/graphene foam/ polymer composites with enhanced mechanical and thermal properties, Composites Part B: Engineering 94 (2016) 102-108.

[60] M. Bazli, H. Ashrafi, A. Jafari, X.-L. Zhao, R. Raman, Y. Bai, Effect of fibers configuration and thickness on tensile behavior of GFRP laminates exposed to harsh environment, Polymers 11(9) (2019) 1401.

[61] M. Bazli, X.-L. Zhao, A. Jafari, H. Ashrafi, Y. Bai, R.S. Raman, H. Khezrza- deh, Mechanical properties of pultruded GFRP profiles under seawater sea sand concrete environment coupled with UV radiation and moisture, Construction and Building Materials 258 (2020) 120369.

[62] M. Bazli, M. Heitzmann, B.V. Hernandez, Hybrid fibre reinforced polymer and seawater sea sand concrete structures: A systematic review on short-term and long-term structural performance, Construction and Building Materials 301 (2021) 124335 .

[63] M. Bazli, X.-L. Zhao, R.S. Raman, Y. Bai, S. Al-Saadi, Bond performance between FRP tubes and seawater sea sand concrete after exposure to seawater condition, Construction and Building Materials 265 (2020) 120342.

[64] M. IRFAN, F. Habib, K. KHALID, S. ALAM, W. IQBAL, Effect of orientation of glass fiber on mechanical properties of GRP composites, Journal of the Chemical Society of Pakistan 32(6) (2010) 265.

[65] S. Erden, K. Sever, Y. Seki, M.J.F. Sarikanat, polymers, Enhancement of the mechanical properties of glass/polyester composites via matrix modification glass/ polyester composite siloxane matrix modification, 11(5) (2010) 732-737.

[66] T. Ishikawa, K. Amaoka, Y. Masubuchi, T. Yamamoto, A. Yamanaka, M. Arai, J. Takahashi, Overview of automotive structural composites technology developments in Japan, Composites Science and Technology 155 (2018) 221-246.

[67] E.P. Najafabadi, M. Bazli, H. Ashrafi, A.V. Oskouei, Effect of applied stress and bar characteristics on the short-term creep behavior of FRP bars, Construction and building materials 171 (2018) 960-968.

[68] T. Huber, S. Bickerton, J. Müssig, S. Pang, M.P. Staiger, Flexural and impact properties of all-cellulose composite laminates, Composites Science and Technology 88 (2013) 92-98.

[69] S. Alsubari, M. Zuhri, S. Sapuan, M. Ishak, R. Ilyas, M.J.P. Asyraf, Potential of natural fiber reinforced polymer composites in sandwich structures: A review on its mechanical properties, 13(3) (2021) 423.

[70] T.-K. Kim, K.-H. Kim, H.-B. Kwon, Aerodynamic characteristics of a tube train, Journal of wind engineering and industrial aerodynamics 99(12) (2011) 1187-1196.

[71] A.G. Koniuszewska, J.W. Kaczmar, Application of polymer based composite materials in transportation, Progress in Rubber Plastics and Recycling Technology 32(1) (2016) 1-24.

[72] I.S.M. Tawakkal, R.A. Talib, K. Abdan, C.N. Ling, Mechanical and physical properties of kenaf-derived cellulose (KDC)-filled polylactic acid (PLA) composites, BioResources 7(2) (2012) 1643-1655.

[73] H. Ashrafi, M. Bazli, A. Vatani Oskouei, L. Bazli, Effect of sequential exposure to UV radiation and water vapor condensation and extreme temperatures on the mechanical properties of GFRP bars, Journal of composites for construction 22(1) (2018) 04017047.

[74] D.H. Mueller, Improving the impact strength of natural fiber reinforced composites by specifically designed material and process parameters, International Nonwovens Journal (4) (2004) 1558925004os-1300405.

[75] T. Corbière-Nicollier, B.G. Laban, L. Lundquist, Y. Leterrier, J.-A. Månson, O.J.R. Jolliet, Conservation, recycling, Life cycle assessment of biofibres replacing glass fibres as reinforcement in plastics, 33(4) (2001) 267-287.

[76] I. Al-Mosawi Ali, Mechanical properties of plants-synthetic hybrid fibers composites, Research Journal of Engineering Sciences (2012) 9472.

[77] S. Joseph, M. Sreekala, Z. Oommen, P. Koshy, S. Thomas, A comparison of the mechanical properties of phenol formaldehyde composites reinforced with banana fibres and glass fibres, Composites Science and Technology 62(14) (2002) 1857-1868.

[78] B.-H. Lee, H.-J. Kim, W.-R. Yu, Fabrication of long and discontinuous natural fiber reinforced polypropylene biocomposites and their mechanical properties, Fibers and Polymers 10(1) (2009) 83-90.

[79] P. Mukherjee, K. Satyanarayana, Structure and properties of some vegetable fibres, Journal of materials science 19(12) (1984) 3925-3934.

[80] H. Iba, T. Chang, Y. Kagawa, Optically transparent continuous glass fibre-reinforced epoxy matrix composite: fabrication, optical and mechanical properties, Composites Science and Technology 62(15) (2002) 2043-2052.

[81] A.V. Oskouei, M. Bazli, H. Ashrafi, M. Imani, Flexural and web crippling properties of GFRP pultruded profiles subjected to wetting and drying cycles in different sea water conditions, Polymer Testing 69 (2018) 417-430.

[82] F. Aramide, P. Atanda, O.J.I.J.o.C.M. Olorunniwo, Mechanical properties of a polyester fibre glass composite, 2(6) (2012) 147-151.

[83] S. Husić, I. Javni, Z.S. Petrović, Thermal and mechanical properties of glass reinforced soy-based polyurethane composites, Composites Science and Technology 65(1) (2005) 19-25.

[84] M.K. Hossain, M.E. Hossain, M.V. Hosur, S.J.C.P.A.A.S. Jeelani, Manufacturing, Flexural and compression response of woven E-glass/polyester-CNF nanophased composites, 42(11) (2011) 1774-1782. 
[85] A. Patnaik, A. Satapathy, S.J.M.P.J. Biswas, Investigations on three-body abrasive wear and mechanical properties of particulate filled glass epoxy composites, 5(2) (2010) 37-48.

[86] A.K. Bledzki, A.A. Mamun, A. Jaszkiewicz, K. Erdmann, Polypropylene composites with enzyme modified abaca fibre, Composites Science and Technology 70(5) (2010) 854-860.

[87] F. Arrakhiz, M. Malha, R. Bouhfid, K. Benmoussa, A. Qaiss, Tensile, flexural and torsional properties of chemically treated alfa, coir and bagasse reinforced polypropylene, Composites Part B: Engineering 47 (2013) 35-41.

[88] Q. Liu, M.T. Shaw, R.S. Parnas, A.M. McDonnell, Investigation of basalt fiber composite aging behavior for applications in transportation, Polymer Composites $27(5)$ (2006) 475-483

[89] T. Kokubo, H. Takadama, How useful is SBF in predicting in vivo bone bioactivity?, Biomaterials 27(15) (2006) 2907-2915

[90] S.K. Chattopadhyay, R. Khandal, R. Uppaluri, A.K. Ghoshal, Bamboo fiber reinforced polypropylene composites and their mechanical, thermal, and morphological properties, Journal of applied polymer science 119(3) (2011) 1619-1626. [91] R. Rana, R. Purohit, A Review on mechanical property of sisal glass fiber reinforced polymer composites, Materials Today: Proceedings 4(2) (2017) 3466-3476. [92] M. Maleque, F. Belal, S. Sapuan, Mechanical properties study of pseudo-stem banana fiber reinforced epoxy composite, The Arabian journal for science and engineering 32(2B) (2007) 359-364.

[93] S.K. Chattopadhyay, R. Khandal, R. Uppaluri, A.K. Ghoshal, Mechanical, thermal, and morphological properties of maleic anhydride-g-polypropylene compatibilized and chemically modified banana-fiber-reinforced polypropylene composites, Journal of applied polymer science 117(3) (2010) 1731-1740.

[94] F. Tanasă, M. Zănoagă, C.A. Teacă, M. Nechifor, A. Shahzad, Modified hemp fibers intended for fiber-reinforced polymer composites used in structural applications-A review. I. Methods of modification, Polymer Composites 41(1) (2020) $5-31$.

[95] S. Biswas, S. Kindo, A. Patnaik, Effect of fiber length on mechanical behavior of coir fiber reinforced epoxy composites, Fibers and Polymers 12(1) (2011) 73-78.

[96] J. Rout, S. Tripathy, M. Misra, A. Mohanty, S. Nayak, The influence of fiber surface modification on the mechanical properties of coir-polyester composites, Polymer Composites 22(4) (2001) 468-476.

[97] S. Sabinesh, C.T. Renald, S. Sathish, Investigation on tensile and flexural properties of cotton fiber reinforced isophthallic polyester composites, International journal of current engineering and technology 2(2) (2014) 213-219.

[98] C. Baley, Analysis of the flax fibres tensile behaviour and analysis of the tensile stiffness increase, Composites Part A: Applied Science and Manufacturing 33(7) (2002) 939-948.

[99] M.A. Hidalgo-Salazar, J.P. Correa, Mechanical and thermal properties of biocomposites from nonwoven industrial Fique fiber mats with Epoxy Resin and Linear Low Density Polyethylene, Results in physics 8 (2018) 461-467.

[100] K. Wötzel, R. Wirth, M. Flake, Life cycle studies on hemp fibre reinforced components and ABS for automotive parts, Die Angewandte Makromolekulare Chemie 272(1) (1999) 121-127.

[101] W. Thielemans, E. Can, S. Morye, R. Wool, Novel applications of lignin in composite materials, Journal of Applied Polymer Science 83(2) (2002) 323-331.

[102] T.M. Le, K.L. Pickering, The potential of harakeke fibre as reinforcement in polymer matrix composites including modelling of long harakeke fibre composite strength, Composites Part A: Applied Science and Manufacturing 76 (2015) 44-53. [103] A. Karmaker, A. Hoffmann, G. Hinrichsen, Influence of water uptake on the mechanical properties of jute fiber-reinforced polypropylene, Journal of Applied Polymer Science 54(12) (1994) 1803-1807.

[104] P. Roe, M.P. Ansell, Jute-reinforced polyester composites, Journal of Materials Science 20(11) (1985) 4015-4020.

[105] X. Liu, G. Dai, Surface modification and micromechanical properties of jute fiber mat reinforced polypropylene composites, Express Polymer Letters 1(5) (2007) 299-307.

[106] M. Tajvidi, S.K. Najafi, M.M. Shekaraby, N. Motiee, Effect of chemical reagents on the mechanical properties of natural fiber polypropylene composites, Polymer composites 27(5) (2006) 563-569

[107] D. Bachtiar, S. Sapuan, A. Khalina, E. Zainudin, K. Dahlan, Flexural and impact properties of chemically treated sugar palm fiber reinforced high impact polystyrene composites, Fibers and Polymers 13(7) (2012) 894-898.

[108] D.C.O. Nascimento, A.S. Ferreira, S.N. Monteiro, R.C.M. Aquino, S.G. Kestur, Studies on the characterization of piassava fibers and their epoxy composites, Composites Part A: Applied Science and Manufacturing 43(3) (2012) 353-362.

[109] Y. Payae, N. Lopattananon, Adhesion of pineapple-leaf fiber to epoxy matrix: The role of surface treatments, Songklanakarin Journal of Science \& Tech- nology 31(2) (2009).

[110] L.U. Devi, S. Bhagawan, S. Thomas, Mechanical properties of pineapple leaf fiber-reinforced polyester composites, Journal of Applied Polymer Science 64(9) (1997) 1739-1748

[111] U. Hujuri, S.K. Chattopadhay, R. Uppaluri, A.K. Ghoshal, Effect of maleic anhydride grafted polypropylene on the mechanical and morphological properties of chemically modified short-pineapple-leaf-fiber-reinforced polypropylene composites, Journal of Applied Polymer Science 107(3) (2008) 1507-1516.

[112] A.P. Irawan, T.P. Soemardi, K. Widjajalaksmi, A.H. Reksoprodjo, Tensile and flexural strength of ramie fiber reinforced epoxy composites for socket prosthesis application, (2011).

[113] P. Joseph, K. Joseph, S. Thomas, Effect of processing variables on the mechanical properties of sisal-fiber-reinforced polypropylene composites, Composites science and Technology 59(11) (1999) 1625-1640.

[114] J. Tusnim, N. Jenifar, M. Hasan, Properties of jute and sheep wool fiber reinforced hybrid polypropylene composites, IOP Conference Series: Materials Science and Engineering, IOP Publishing, 2018, p. 012029.

[115] N. Hameed, P. Sreekumar, B. Francis, W. Yang, S.J.C.P.A.A.S. Thomas, Manufacturing, Morphology, dynamic mechanical and thermal studies on poly (styrene-co-acrylonitrile) modified epoxy resin/glass fibre composites, 38(12) (2007) 2422-2432

[116] J. Naveen, M. Jawaid, P. Amuthakkannan, M. Chandrasekar, Mechanical and physical properties of sisal and hybrid sisal fiber-reinforced polymer composites, Mechanical and physical testing of biocomposites, fibre-reinforced composites and hybrid composites, Elsevier2019, pp. 427-440.

[117] T. Sathishkumar, S. Satheeshkumar, J.J.J.o.r.p. Naveen, composites, Glass fiber-reinforced polymer composites-a review, 33(13) (2014) 1258-1275.

[118] M.A. Faizal, Y.K. Beng, M.N. Dalimin, Tensile property of hand lay-up plain-weave woven eglass/polyester composite: Curing pressure and Ply arrangement effect, Born. Sci 19 (2006) 27-34

[119] E.R. Fuchs, F.R. Field, R. Roth, R.E.J.C.s. Kirchain, technology, Strategic materials selection in the automobile body: Economic opportunities for polymer composite design, 68(9) (2008) 1989-2002.

[120] T.-K. Kim, K.-H. Kim, H.-B.J.J.o.w.e. Kwon, i. aerodynamics, Aerodynamic characteristics of a tube train, 99(12) (2011) 1187-1196

[121] F.M. Al-Oqla, S. Sapuan, Natural fiber reinforced polymer composites in industrial applications: feasibility of date palm fibers for sustainable automotive industry, Journal of Cleaner Production 66 (2014) 347-354.

[122] A.M. Visco, L. Calabrese, P. Cianciafara, Modification of polyester resin based composites induced by seawater absorption, Composites part A: applied science and manufacturing 39(5) (2008) 805-814

[123] F. Wang, Y. Ji, X. Yu, H. Chen, Z. Yue, Ablation damage assessment of aircraft carbon fiber/epoxy composite and its protection structures suffered from lightning strike, Composite Structures 145 (2016) 226-241.

[124] L. Bazli, M. Yusuf, A. Farahani, M. Kiamarzi, Z. Seyedhosseini, M. Nezhadmansari, M. Aliasghari, M. Iranpoor, Application of composite conducting polymers for improving the corrosion behavior of various substrates: A Review, Journal of Composites and Compounds 2(5) (2020) 228-240.

[125] I. Sultana, M.M. Rahman, S. Li, J. Wang, C. Wang, G.G. Wallace, H.-K. Liu, Electrodeposited polypyrrole (PPy)/para (toluene sulfonic acid)(pTS) free-standing film for lithium secondary battery application, Electrochimica acta 60 (2012) 201-205.

[126] M.A. Fariborz SharifianJazi Amirhossein Moghanian, Fatemeh Hasan beigi, Alireza Najari, Synthesis and investigation the mechanical properties of PET polymer matrix composite reinforced with $\mathrm{SiO} 2$ in civil engineering by TTO model, The 5th National and the 1st International Conference on Modern Materials and Structures in Civil Engineering, Amirkabir University of Technology (Tehran Polytechnic), Tehran, Iran (2016)

[127] L. Bazli, S. Eskandarinezhad, N. Kakur, V. Ramachandran, A. Bacigalupe, M. Mansilla, M. Escobar, Electrical properties of polymer blend composites based on Silicone rubber/EPDM/clay for high voltage insulators, Journal of Composites and Compounds 3(6) (2021) 18-24.

[128] J. Daraei, Production and characterization of PCL (Polycaprolactone) coated $\mathrm{TCP} /$ nanoBG composite scaffolds by sponge foam method for orthopedic applications, Journal of Composites and Compounds 2(2) (2020) 44-49.

[129] M. Ramesh, K. Palanikumar, K.H. Reddy, Plant fibre based bio-composites: Sustainable and renewable green materials, Renewable and Sustainable Energy Reviews 79 (2017) 558-584.

[130] T. Mukherjee, N. Kao, PLA based biopolymer reinforced with natural fibre: a review, Journal of Polymers and the Environment 19(3) (2011) 714-725.

[131] M. Sanjay, G. Arpitha, L.L. Naik, K. Gopalakrishna, B. Yogesha, Applications of natural fibers and its composites: An overview, Natural Resources 7(3) 
(2016) 108-114

[132] U. Bongarde, V. Shinde, Review on natural fiber reinforcement polymer composites, International Journal of Engineering Science and Innovative Technology 3(2) (2014) 431-436.

[133] T. Sen, H.J. Reddy, Application of sisal, bamboo, coir and jute natural composites in structural upgradation, International journal of innovation, management and technology 2(3) (2011) 186 .

[134] M. Harris, Carbon fibre: the wonder material with a dirty secret, The Guardian, Guardian News and Media 22 (2017).

[135] M. Jawaid, H.A. Khalil, Cellulosic/synthetic fibre reinforced polymer hybrid composites: A review, Carbohydrate polymers 86(1) (2011) 1-18.

[136] P. Wambua, J. Ivens, I. Verpoest, Natural fibres: can they replace glass in fibre reinforced plastics?, Composites science and technology 63(9) (2003) 12591264.

[137] M. Norhidayah, A.A. Hambali, M.Y. bin Yaakob, M. Zolkarnain, H. Saifuddin, A review of current development in natural fiber composites in automotive applications, Applied Mechanics and Materials, Trans Tech Publ, 2014, pp. 3-7.

[138] J. Holbery, D. Houston, Natural-fiber-reinforced polymer composites in automotive applications, Jom 58(11) (2006) 80-86.

[139] L. Mohammed, M.N. Ansari, G. Pua, M. Jawaid, M.S. Islam, A review on natural fiber reinforced polymer composite and its applications, International Jour- nal of Polymer Science 2015 (2015)

[140] B.C. Suddell, Industrial fibres: recent and current developments, Proceedings of the symposium on natural fibres, FAO and CFC Rome, 2008, pp. 71-82.

[141] V. Chauhan, T. Kärki, J. Varis, Review of natural fiber-reinforced engineering plastic composites, their applications in the transportation sector and processing techniques, Journal of Thermoplastic Composite Materials (2019) 0892705719889095.

[142] T. Khan, M.T.B. Hameed Sultan, A.H. Ariffin, The challenges of natural fiber in manufacturing, material selection, and technology application: a review, Journal of Reinforced Plastics and Composites 37(11) (2018) 770-779.

[143] N. Saba, M. Jawaid, M. Sultan, O.Y. Alothman, Green biocomposites for structural applications, Green Biocomposites, Springer2017, pp. 1-27.

[144] M. Arefian, M. Hojjati, I. Tajzad, A. Mokhtarzade, M. Mazhar, A. Jamavari, A review of Polyvinyl alcohol/Carboxymethyl cellulose (PVA/CMC) composites for various applications, Journal of Composites and Compounds 2(3) (2020) 6976.

[145] A. Nouri, B. Faraji Dizaji, N. Kianinejad, A. Jafari Rad, S. Rahimi, M. Irani, F. Sharifian Jazi, Simultaneous linear release of folic acid and doxorubicin from ethyl cellulose/chitosan/g-C3N4/MoS2 core-shell nanofibers and its anticancer properties, Journal of Biomedical Materials Research Part A 109(6) (2021) 903914. 